\title{
Comparison Between Cefotiam And Cefotiam / Netilmycin Antibiotic Therapy for Grade III Open Tibial Fractures
}

\author{
NN Hidajat, MD, H Herman, MD \\ Department of Orthopaedic Surgery, Padjadjaran State University-Hasan Sadikin General Hospital, \\ Bandung, Indonesia
}

\begin{abstract}
We studied the effect of the addition of the bacteriostatic agent, netilmycin, to cefotiam treatment as prophylactic antibiotics against infection for grade III open tibial fractures. From 45 eligible cases, assigned randomly to a control group that receive only cefotiam, and the treatment group that receive netilmycin in addition to cefotiam. We observed that the clearing of infection occurred earlier in the cefotiam /netilmycin group. We found that 3-day administration of cefotiam-netilmycin is superior to 3-day administration of cefotiam only. It is equivalent to 5-day treatment with cefotiam alone.
\end{abstract}

Key Words:

Grade III open fractures, Infection, cefotiam, Netilmycin

\section{INTRODUCTION}

Tibial fractures are the most common fractures of the long bones. About one fourth of these are open fractures, where bones involved are exposed to the environment through an open wound ${ }^{1,2}$. Major causes of these fractures include motor vehicle accidents and sports injuries. Low-energy injuries usually result in traverse fractures, which is usually more stable and with less displacement. Torsional injuries result in oblique or spiral fractures and are inherently unstable. Highenergy trauma is usually associated with comminuted fractures and they are commonly compounded by multiple injuries. The tibia is medially and anteriorly located in the leg with limited soft tissue lining between the bony periosteum and the superficial skin. Any fractures to the tibia, therefore, tend to break through the skin resulting in open fracture. Depending on the quality of the reduction, tibial fractures should heal adequately. The presence of the open wound however, complicates management. Wounds introduce microbes, locally and systemically. It will also reduce the availability of healthy soft tissue for wound closure, and hence pose hazards to fracture healing/bony union.

The prevention of wound and systemic sepsis is vital or the management of open tibial fractures. This is attained through the administration of prophylactic antibiotics and tetanus toxoid ${ }^{3-6}$, copious and thorough wound irrigation ${ }^{7}$, and debridement of necrotic and devascularized tissue ${ }^{8}$. This is then followed by reduction of the fracture and primary stabilization ${ }^{9}$. Open fractures are usually classified into 3 types according to Gustilo and Anderson ${ }^{10,11}$. Inevitably infection is a serious complication of open fractures. Studies have revealed that debridement, while able to decrease infection, are insufficient for achievement of prompt infection clearance ${ }^{6,10}$. Various antibiotics groups have been tried and tested. Recommendations include the use of first or second generation cephalosporins for type I/II fractures; the addition of an aminoglycoside for type IIIA fractures; and further addition of penicillin for type IIIB fractures.

We regularly use second generation cephalosporin, cefotiam, as a single agent in the treatment of open grade III tibial fractures. In the current study we would like to validate the value of adding the bacteriostatic aminoglycoside agent, netilmycin, in the management of infection for these cases. Furthermore, we would also like to elucidate the optimal length of administration of the combination between netilmycin with cefotiam. Although risking an increase in side effects and cost with the use of such a combination, we reasoned that reduction in length of treatment and rate of complication may compensate for those drawbacks.

\section{MATERIALS AND METHODS}

The subjects were randomly assigned to control (20 subjects) and treatment groups (25 subjects). Subject randomization was achieved by using a random number table. Inclusion criteria were: age ranging from 15 to $45 \mathrm{y}$, open grade III tibial fractures resulting from motor vehicle accidents, with time interval to debridement less than 8 hours, without additional/multiple trauma. Exclusion criteria were pathological fracture, history of current and prolonged corticosteroid use, liver function disturbance or renal failure. Ethics approval was obtained from the Ethics Committee of the School of Medicine, Padjadjaran State University Hasan Sadikin General Hospital and in accordance with the Helsinki Declaration 1975.

Specimens were collected at day 0 (D0), post-debridement,

Corresponding Author: Nucki Nursjamsji Hidajat, Dept. of Orthopaedic Surgery, School of Medicine, Padjadjaran State University,

Bandung 40161, Indonesia_Email: nucki@cbn.net.id, herry_herman@yahoo.com 
Table I: Distribution of age and time to debridement

\begin{tabular}{|lccc|}
\hline & Control & Treatment & p-value \\
\hline Age (years) & mean $( \pm 2$ SE) & \pm 2SE) & 0.87 \\
Time to debridement (hours) & $26.1 \pm 3.66$ & $25.68 \pm 3.525$ & 0.37 \\
\hline
\end{tabular}

Table Il: Distribution of bacterial species contaminating wounds

\begin{tabular}{|lcc|}
\hline Bacterial strain & Number of specimens & Percentage \\
\hline Staphylococcus Aureus & 17 & $39.6 \%$ \\
Bacillus Subtilis & 12 & $27.9 \%$ \\
Klebsiella Pneumoniae & 3 & $6.9 \%$ \\
Enterobacter sp & 7 & $16.3 \%$ \\
Pseudomonas sp. & 4 & $9.3 \%$ \\
\hline
\end{tabular}

Table III: Proportion of infectious and non-infectious specimens from control and treatment group after specified number of days of antibiotics treatment

\begin{tabular}{|lccccc|}
\hline & \multicolumn{1}{c}{ Control Group } & \multicolumn{2}{c|}{ Treatment Group } & p value \\
\hline Day 0 & $>10^{5}$ & $<10^{5}$ & $>10^{5}$ & $<10^{5}$ & 0.4 \\
Day 3 & 19 & 1 & 22 & 3 & $0.02^{*}$ \\
Day 5 & 13 & 7 & 8 & 17 & 0.25 \\
\hline
\end{tabular}

*statistically significant

day 3 (D3) and day 5 (D5) of treatment. With aseptic technique, approximately 1 gr. of tissue specimen was collected from the base of the wound and transferred to a tube containing $9 \mathrm{mls}$ of sterile physiological saline. Samples were then homogenized. The homogenate was serially diluted 1:10 up to $10^{-6 / 7}$ dilution prior to plating onto blood agar. The resulting number of colonies was counted. We stratified samples based on Colony-forming units (CFU) per gram of tissue - infectious samples have more than $10^{5}$ $\mathrm{CFU} /$ grams and those that are non-infectious, $<10^{5}$ $\mathrm{CFU} /$ grams.

The doses used were $80 \mathrm{mg} / \mathrm{kg}$ body weight for cefotiam and $5 \mathrm{mg} / \mathrm{kg}$ body weight for netilmycin. They were delivered in two doses and administered intravenously for five days.

We utilized standard chi square test analysis for comparison of the proportion of infectious and non-infectious specimens collected on various days from both groups.

\section{RESULTS}

Most common contaminating bacteria post debridement was Staphylococcus aureus (40\% of all samples) followed by Bacillus subtilis and Enterobacter sp. This is not surprising, as Staphylococcus aureus is the most commonly commensal bacteria on skin, and is in agreement with results reported by for a similar study by Gustilo $\mathrm{A}^{10}$ and Patzakis $\mathrm{MJ}^{12}$. Bacillus subtilis is the bacteria commonly found on dirt and soil, which may explain its presence in a contaminated wound, and is also in agreement with the previous study by Gustilo ${ }^{10}$ and Patzakis ${ }^{12}$. Enterobacter is a commensal bacterium of gastrointestinal tract, thus, with the sanitation condition in the study region, it is not surprising that its presence is still common in the soil.

Ninety-one per cent of the specimens collected after debridement were proven to be infectious. There was significant reduction of infectivity correlating to the length of treatment in both groups (Table III). For the control group, the proportion of specimens with infection at D0, D3 and D5 were significantly different. For the treatment group, the difference were highly significant between D3 and D0 $(p<0.01)$, but not so between D5 and D3 ( $p=0.09)$. When we compare between the control and treatment groups for D3 and D5; both groups differ significantly at D3 $(\mathrm{p}=0.02)$ but not at D5 $(\mathrm{p}=0.25)$.

\section{DISCUSSION}

In our study, $91 \%$ of specimens from the wounds after debridement were infected. A previous study by Gustilo ${ }^{10}$ revealed that $70 \%$ of post debridement specimens are still infected. These differences may be attributed to the state of local sanitation in the study area and the initial management at the accident site, which is non-existent in our study.

At D0, the proportion of infected specimens was comparable between controls and treatment. At D3 of antibiotics administration, the decrease in rate of infected specimen were significant for both groups $(\mathrm{p}=0.018$ for control group and $\mathrm{p}<0.01$ for treatment group). At D5, there was further 
reduction in the proportion of specimens with infection in the control group, but not in the treatment group $(\mathrm{p}=0.05$ and $\mathrm{p}=0.09$ respectively). This means that for the control group, additional days of antibiotic administration were beneficial to further control the infection. However, for the treatment group, reduction of infection was optimal at D3 of antibiotic administration. Reduction of rate of infection at D3 is significantly better in the treatment group compared to the control group $(\mathrm{p}=0.02)$.

\section{CONCLUSION}

We conclude that the addition of bacteriostatic agent netilmycin to cefotiam helps to provide more effective control of wound infection. Infection control can be achieved in a shorter period of time compared to using of cefotiam only. We propose that addition of bacteriostatic agent such as netilmycin in the standard antibiotic regime in the management of open fractures.

\section{ACKNOWLEDGMENTS}

We would like to thank the Dean of School of Medicine at Padjadjaran State University, and the Director of Hasan Sadikin General Hospital for the cooperation and support for this study. The author declares no competing interest. 


\section{REFERENCES}

1. Court-Brown CM, McBirnie J, The epidemiology of tibial fractures. J Bone Joint Surg 1995; 77-B(3): 417-21.

2. McGrath L, Royston S. Fractures of the tibial shaft. Surgery 2003; 21(9): 231-5.

3. Bergman BR. Antibiotic prophylaxis in open and closed fractures: a controlled clinical trial. Acta Orthop Scand 1982; 53(1): 5762.

4. Dellinger EP. Antibiotic prophylaxis in trauma: penetrating abdominal injuries and open fractures. Rev Infect Dis 1991; 13 Suppl 10: S847-57.

5. Dellinger EP, Caplan ES, Weaver LD, Wertz MJ, Droppert BM, Hoyt N et al. Duration of preventive antibiotic administration for open extremity fractures. Arch Surg 1988; 123(3): 333-9.

6. Patzakis MJ. The use of antibiotics in open fractures. Surg Clin North Am 1975; 55(6): 1439-44.

7. Bhandari M, Schemitsch EH, Adili A, Lachowski RJ, Shaughnessy SG. High and low pressure pulsatile lavage of contaminated tibial fractures: an in vitro study of bacterial adherence and bone damage J Orthop Trauma 1999; 13(8): 526-33.

8. Gustilo RB, Merkow RL, Templeman D. The management of open fractures. J Bone Joint Surg 1990; 72-A(2): $299-304$.

9. Chapman MW, Mahoney M. The role of early internal fixation in the management of open fractures. Clin Orthop Relat Res 1979; (138): 120-31.

10. Gustilo RB, Anderson JT. Prevention of infection in the treatment of one thousand and twenty-five open fractures of long bones: retrospective and prospective analyses. J Bone Joint Surg 1976; 58-A(4): 453-8.

11. Gustilo RB, Gruninger RP, Davis T. Classification of type III (severe) open fractures relative to treatment and results. Orthopedics 1987; 10(12): 1781-8.

12. Patzakis MJ, Wilkins J, Moore TM. Considerations in reducing the infection rate in open tibial fractures. Clin Orthop Relat Res 1983(178): 36-41. 